\title{
Winogradskyella pacifica sp. nov., a marine bacterium of the family Flavobacteriaceae
}

\author{
Correspondence \\ Olga I. Nedashkovskaya \\ olganedashkovska@piboc.dvo.ru \\ or \\ olganedashkovska@yahoo.com
}

\author{
Seung Bum Kim ${ }^{1}$ and Olga I. Nedashkovskaya ${ }^{2}$ \\ ${ }^{1}$ Department of Microbiology, School of Bioscience and Biotechnology, Chungnam National \\ University, 220 Gung-dong, Yuseong, Daejeon 305-764, Republic of Korea \\ ${ }^{2}$ Pacific Institute of Bioorganic Chemistry of the Far-Eastern Branch of the Russian Academy of \\ Sciences, Pr. 100 Let Vladivostoku 159, 690022 Vladivostok, Russia
}

The genus Winogradskyella is a member of the family Flavobacteriaceae (Bernardet et al., 2002) and at the time of writing comprises seven recognized species: $W$. arenosi, $W$. echinorum, W. epiphytica, W. eximia, W. poriferorum, W. rapida and $W$. thalassocola (Lau et al., 2005; Nedashkovskaya et al., 2005, 2009; Romanenko et al., 2009; Pinhassi et al., 2009). To date, the genus Winogradskyella is represented by marine bacteria isolated from seawater, sediments, seaweed and animals. Phylogenetically, the genus Winogradskyella forms a cluster with the genera Psychroserpens, Formosa, Bizionia, Lacinutrix and Gaetbulibacter. In this work, we report the detailed taxonomic characterization of a novel marine bacterium belonging to the genus Winogradskyella.

Strain KMM $6019^{\mathrm{T}}$ was isolated from a coastal seawater sample collected from Amursky Bay, Gulf of Peter the Great, the East Sea (also known as the Sea of Japan). For strain isolation, $0.1 \mathrm{ml}$ seawater was transferred onto plates of marine agar 2216 (MA; Difco). After primary isolation and purification, the strain was cultivated at $28{ }^{\circ} \mathrm{C}$ on the same medium and stored at $-80{ }^{\circ} \mathrm{C}$ in marine broth (Difco) supplemented with $20 \%(\mathrm{v} / \mathrm{v})$ glycerol.

The GenBank/EMBL/DDBJ accession number for the 16S rRNA gene sequence of Winogradskyella pacifica KMM $6019^{\top}$ is GQ181061.
The phylogenetic position of strain KMM $6019^{\mathrm{T}}$ was determined from its almost-complete 16S rRNA gene sequence (1424 bp). Genomic DNA extraction, PCR and sequencing of $16 \mathrm{~S}$ rRNA genes were performed by using previously described procedures (Cho et al., 2006). The sequences obtained were aligned with those of representative members of selected genera belonging to the family Flavobacteriaceae by using PHYDIT version 3.1 (http://plaza. snu.ac.kr/ jchun/phydit/). Phylogenetic trees were inferred by using suitable programs of the PHYLIP package (Felsenstein, 1993). Phylogenetic distances were calculated from the two-parameter model (Kimura, 1980), and the trees were constructed on the basis of the neighbourjoining (Saitou \& Nei, 1987), maximum-likelihood (Felsenstein, 1993) and maximum-parsimony (Kluge \& Farris, 1969) algorithms. Bootstrap analysis was performed with 1000 resampled datasets, using SEQBOOT and CONSENSE programs of the PHYLIP package.

A comparative analysis of the almost-complete 16S rRNA gene sequence of strain $\mathrm{KMM} 6019^{\mathrm{T}}$ revealed that the strain formed a distinct evolutionary lineage within the genus Winogradskyella, a member of the family Flavobacteriaceae, phylum Bacteroidetes (Fig. 1). The $16 \mathrm{~S}$ 


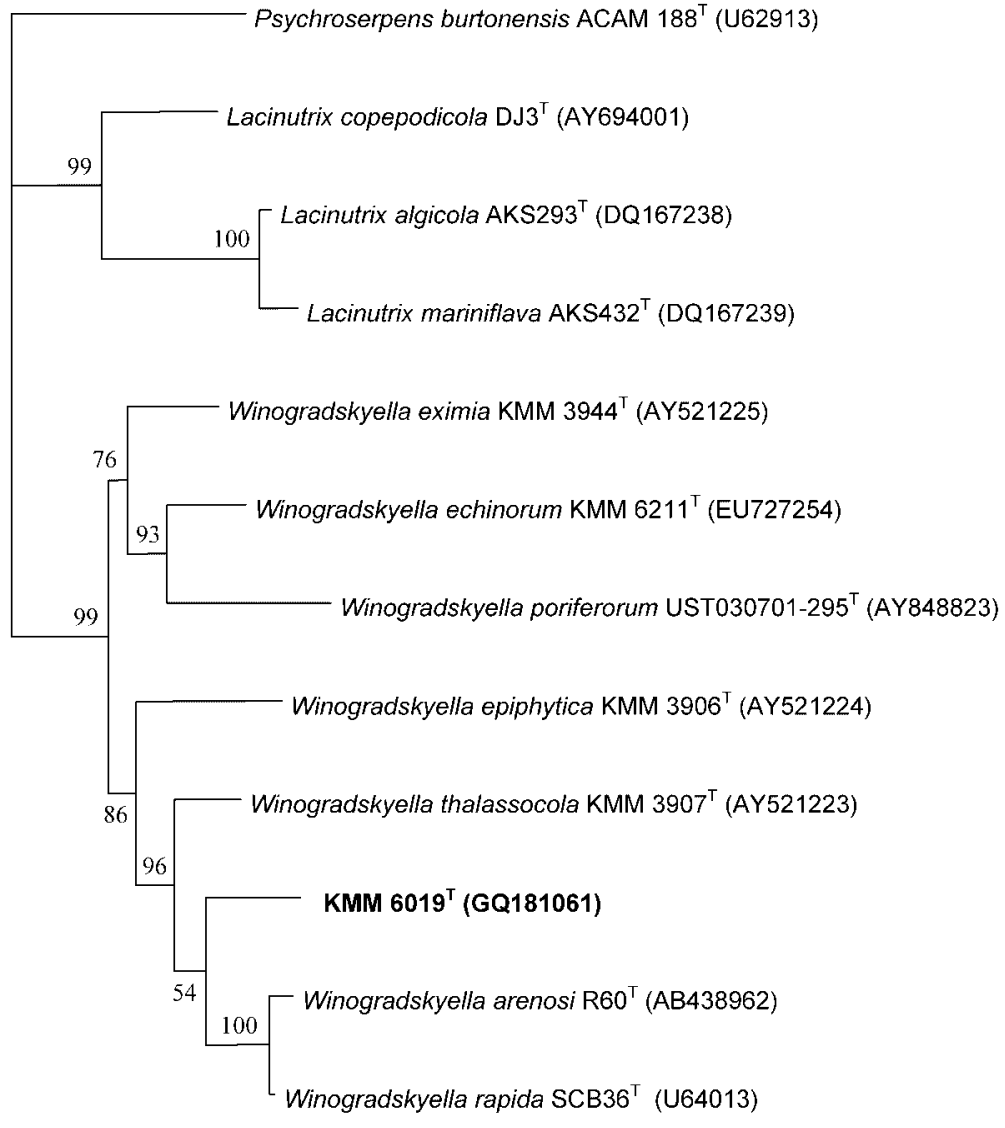

0.01
Fig. 1. Neighbour-joining tree of the genus Winogradskyella and related taxa. The identical topology was obtained in maximumlikelihood and maximum-parsimony trees. Values at nodes are the bootstrap support (\%) based on a 1000 resampled dataset. Bar, 0.01 substitutions per nucleotide position.
rRNA gene sequence similarity between the novel isolate and the type strains of the recognized species of the genus Winogradskyella was $94.0-97.8 \%$. The closest relative was Winogradskyella thalassocola $\mathrm{KMM} 3907^{\mathrm{T}}$, with $97.8 \%$ sequence similarity. This value is lower than the recommended extreme value for species delineation (about 99\%) without determination of the degree of DNA-DNA reassociation between the relative bacterial strains (Stackebrandt \& Ebers, 2006).

DNA was isolated following the method of Marmur (1961) and the DNA G $+\mathrm{C}$ content was determined by the thermal denaturation method (Marmur \& Doty, 1962). The DNA $\mathrm{G}+\mathrm{C}$ content of $\mathrm{KMM} 6019^{\mathrm{T}}$ was $35.3 \mathrm{~mol} \%$. This value is in the range of the DNA $\mathrm{G}+\mathrm{C}$ content of the recognized Winogradskyella species (Table 1).

To determine whole-cell fatty acid composition by the MIDI procedure, strain KMM $6019^{\mathrm{T}}$ was grown at $28{ }^{\circ} \mathrm{C}$ for $48 \mathrm{~h}$ on MA. The fatty acids accounting for more than $1 \%$ of the total were iso- $\mathrm{C}_{15: 0}(15.8 \%)$, iso- $\mathrm{C}_{15: 1}(11.7 \%)$, anteiso- $\mathrm{C}_{15: 0}(11.1 \%)$, iso- $\mathrm{C}_{15: 0} 3-\mathrm{OH}(8.9 \%)$, iso- $\mathrm{C}_{16: 0}$ $3-\mathrm{OH}(8.6 \%), \mathrm{C}_{15: 0}(6.2 \%)$, iso- $\mathrm{C}_{17: 0} 3-\mathrm{OH}(5.3 \%)$, summed feature 3 comprising iso- $\mathrm{C}_{15: 0} 2-\mathrm{OH}$ and/or $\mathrm{C}_{16: 1} \omega 7 c(4.2 \%), \mathrm{C}_{15: 1} \omega 6 c(3.1 \%)$, iso- $\mathrm{C}_{16: 1} \mathrm{H}(2.2 \%)$, anteiso- $\mathrm{C}_{15: 1}(2.1 \%)$, iso- $\mathrm{C}_{14: 0}(1.8 \%)$, iso- $\mathrm{C}_{16: 0}(1.4 \%)$,
$\mathrm{C}_{15: 0} 2-\mathrm{OH}(1.4 \%)$, iso- $\mathrm{C}_{17: 1} \omega 9 c(1.4 \%), \mathrm{C}_{17: 1} \omega 6 c(1.4 \%)$, $\mathrm{C}_{15: 0} 3-\mathrm{OH}(1.3 \%)$ and $\mathrm{C}_{17: 0} 3-\mathrm{OH}(1.3 \%)$. The cellular fatty acids of strain KMM $6019^{\mathrm{T}}$ are consistent with those reported for the recognized species of the genus Winogradskyella (Nedashkovskaya et al., 2005, 2009; Lau et al., 2005).

The physiological, morphological and biochemical characteristics of strain KMM $6019^{\mathrm{T}}$ were studied as described previously (Nedashkovskaya et al., 2003, 2004). API 20 E, API $20 \mathrm{NE}$ and API ZYM galleries (bioMérieux) were also used for examination of the phenotypic features of the strain studied according to the manufacturer's instructions, except that the galleries were incubated at $28{ }^{\circ} \mathrm{C}$.

The main physiological and biochemical characteristics of strain KMM $6019^{\mathrm{T}}$ are given in the species description and in Table 1. The novel isolate shared many phenotypic properties in common with the Winogradskyella species. It was a strictly aerobic and motile-by-gliding organism that produced alkaline phosphatase, catalase, gelatinase and oxidase, and required $\mathrm{NaCl}$ or seawater for growth. However, it can clearly be differentiated from the recognized species of the genus Winogradskyella by its ability to utilize inositol and sorbitol and to produce hydrogen sulphide. Several traits such as hydrolysis of agar, 
Table 1. Phenotypic characteristics differentiating strain $\mathrm{KMM} 6019^{\top}$ from the recognized Winogradskyella species

Strains: 1, KMM $6019^{\mathrm{T}}$; 2, W. thalassocola KMM $3907^{\mathrm{T}}$; 3, W. arenosi KMM $3968^{\mathrm{T}} ; 4$, W. echinorum KMM 6211 ${ }^{\mathrm{T}}$; 5, W. epiphytica KMM 3906 ${ }^{\mathrm{T}}$; 6 , W. eximia KMM $3944^{\mathrm{T}}$; 7, W. poriferorum UST030701-295 ${ }^{\mathrm{T}}$; 8, W. rapida SCB36 ${ }^{\mathrm{T}}$. Data are from Lau et al. (2005), Nedashkovskaya et al. (2005, 2009), Pinhassi et al. (2009), Romanenko et al. (2009) and this study. All strains were positive for the following: respiratory metabolism; gliding motility; oxidase, catalase and alkaline phosphatase activities; a requirement for $\mathrm{Na}^{+}$ions for growth; gelatin hydrolysis; susceptibility to carbenicillin and lincomycin; and resistance to benzylpenicillin, gentamicin, kanamycin, neomycin, polymyxin B and streptomycin. All strains were negative for the following: nitrate reductase activity; flexirubin-type pigments; indole and acetoin production; hydrolysis of urea and chitin; acid production from L-arabinose, D-galactose, D-lactose, melibiose, L-rhamnose, D-xylose, adonitol, dulcitol, inositol, sorbitol and citrate; and utilization of L-arabinose, D-lactose, malonate and citrate. ND, Data are not available.

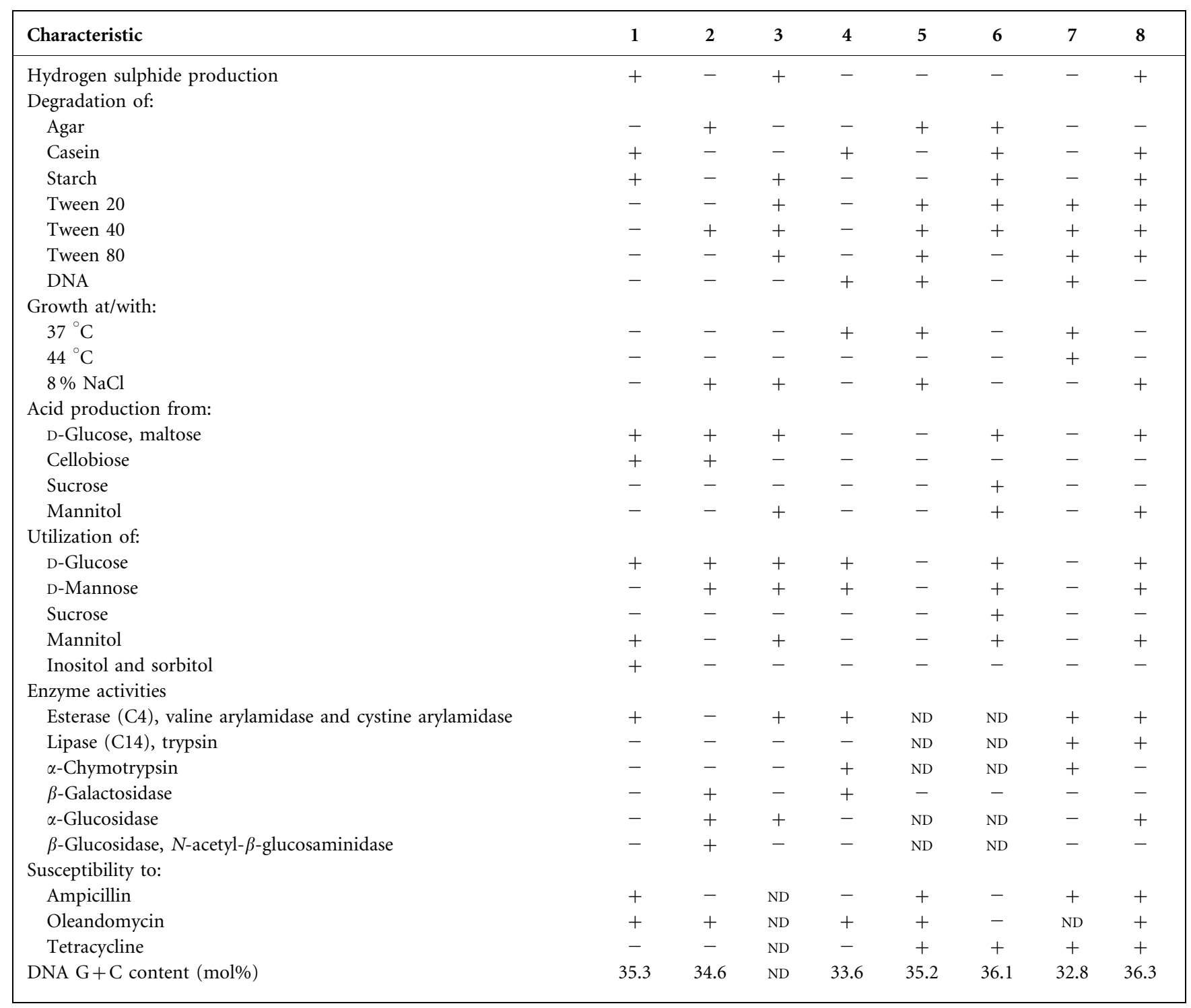

casein, starch and Tween 40, growth with $8 \% \mathrm{NaCl}$ and utilization of D-mannose and mannitol could be useful for separation of the strain under study from its nearest phylogenetic neighbour, $W$. thalassocola $\mathrm{KMM} 3907^{\mathrm{T}}$ (Table 1). The presence of esterase $(\mathrm{C} 4)$, valine arylamidase and cystine arylamidase activities and the absence of $\beta$ galactosidase, $\alpha$-glucosidase, $\beta$-glucosidase and $N$-acetyl- $\beta$ glucosaminidase activities, determined in KMM $6019^{\mathrm{T}}$ cells using the API ZYM gallery, contrasted with the results for W. thalassocola KMM $3907^{\mathrm{T}}$ (Table 1). It should be noted that the latter strain has been described as $\beta$-galactosidasenegative (Nedashkovskaya et al., 2005). This discrepancy could be due to the use of different methods to assay for $\beta$ galactosidase activity. Phenotypic characteristics differentiating strain KMM $6019^{\mathrm{T}}$ from other Winogradskyella species are shown in Table 1.

Consequently, on the basis of phylogenetic, genotypic, chemotaxonomic and phenotypic data, strain KMM $6019^{\mathrm{T}}$ should be classified as the type strain of a novel species 
within the genus Winogradskyella, for which the name Winogradskyella pacifica sp. nov. is proposed.

\section{Description of Winogradskyella pacifica sp. nov.}

Winogradskyella pacifica (pa.ci'fi.ca. L. fem. adj. pacifica pacific, pertaining to the Pacific Ocean from where the type strain was isolated).

Cells are heterotrophic, strictly aerobic, motile by gliding, Gram-negative rods, $0.4-0.5 \mu \mathrm{m}$ wide and $1.0-2.3 \mu \mathrm{m}$ long. On marine agar, colonies are $2-3 \mathrm{~mm}$ in diameter, circular, shiny with entire edges and yellow-coloured. Growth occurs at $4-30{ }^{\circ} \mathrm{C}$ and with $1-5 \% \mathrm{NaCl}$ (optimum $1-3 \%$ $\mathrm{NaCl}$ ). Produces catalase and oxidase. Arginine dihydrolase, lysine decarboxylase, ornithine decarboxylase and tryptophan deaminase activities are absent. Aesculin, gelatin, casein and starch are hydrolysed but agar, DNA, Tweens 20, 40 and 80, urea, cellulose (CM-cellulose and filter paper) and chitin are not. Acid is produced from cellobiose, D-glucose and maltose, but not from Larabinose, D-galactose, D-fructose, D-lactose, melibiose, raffinose, L-rhamnose, sucrose, xylose, $\mathrm{N}$-acetylglucosamine, glycerol or mannitol. Utilizes inositol, mannitol and sorbitol, but not L-arabinose, D-lactose, mannose, sucrose, $\mathrm{N}$-acetylglucosamine, adipate, caprate, citrate, gluconate, malate, malonate and phenylacetate. According to the API ZYM gallery, esterase (C4) (weakly), esterase lipase (C8), leucine arylamidase, cystine arylamidase, valine arylamidase, alkaline phosphatase, acid phosphatase and naphtholAS-BI-phosphohydrolase activities are present, but lipase (C14), trypsin, $\alpha$-chymotrypsin, $\alpha$ - and $\beta$-galactosidases, $\beta$ glucuronidase, $\alpha$ - and $\beta$-glucosidases, $N$-acetyl- $\beta$-glucosaminidase, $\alpha$-mannosidase and $\alpha$-fucosidase activities are absent. No flexirubins are formed. Nitrate is not reduced. Hydrogen sulphide is produced, but indole and acetoin are not. Brown pigment is not formed on tyrosine medium. Susceptible to ampicillin, benzylpenicillin, carbenicillin, cefalexin, chloramphenicol, erythromycin, lincomycin, ofloxacin, oleandomycin, rifampicin and vancomycin; and resistant to cefazolin, doxycycline, gentamicin, kanamycin, neomycin, nalidixic acid, oxacillin, polymyxin B, streptomycin and tetracycline. The predominant fatty acids are iso- $\mathrm{C}_{15: 0}$, iso- $\mathrm{C}_{15: 1}$, anteiso- $\mathrm{C}_{15: 0}$, iso- $\mathrm{C}_{15: 0} 3-\mathrm{OH}$, iso$\mathrm{C}_{16: 0} 3-\mathrm{OH}, \mathrm{C}_{15: 0}$, iso- $\mathrm{C}_{17: 0} 3-\mathrm{OH}$ and summed feature 3 comprising iso- $\mathrm{C}_{15: 0} 2-\mathrm{OH}$ and/or $\mathrm{C}_{16: 1} \omega 7 c$. The DNA $\mathrm{G}+\mathrm{C}$ content of the type strain is $35.3 \mathrm{~mol} \%$.

The type strain, KMM $6019^{\mathrm{T}}\left(=\mathrm{KCTC} 22997^{\mathrm{T}}=\mathrm{LMG}\right.$ $22568^{\mathrm{T}}$ ), was isolated from shallow seawater collected from Amursky Bay, the East Sea, also known as the Sea of Japan.

\section{Acknowledgements}

This research was supported by grants from the Russian Foundation for Basic Research (RFBR) no. 08-04-00099, Presidium of the Russian Academy of Sciences 'Molecular and Cell Biology' and by the State Contract from the Federal Agency for Science and Innovations of the Russian Federation. S. B. K. acknowledges support from the Survey of Indigenous Biological Resources of Korea Program sponsored by the
National Institute of Biological Resources (NIBR) under the Ministry of Environment, Korea.

\section{References}

Bernardet, J.-F., Nakagawa, Y. \& Holmes, B. (2002). Proposed minimal standards for describing new taxa of the family Flavobacteriaceae and emended description of the family. Int J Syst Evol Microbiol 52, 1049-1070.

Cho, S. H., Han, J. H., Seong, C. N. \& Kim, S. B. (2006). Phylogenetic diversity of acidophilic sporoactinobacteria isolated from various soils. J Microbiol 44, 600-606.

Felsenstein, J. (1993). PHYLIP (phylogeny inference package), version 3.5c. Distributed by the author. Department of Genome Sciences, University of Washington, Seattle, USA.

Kimura, M. (1980). A simple method for estimating evolutionary rates of base substitutions through comparative studies of nucleotide sequences. J Mol Evol 16, 111-120.

Kluge, A. G. \& Farris, J. S. (1969). Quantitative phyletics and the evolution of anurans. Syst Zool 18, 1-32.

Lau, S. C. K., Tsoi, M. M. Y., Li, X., Plakhotnikova, I., Dobretsov, S., Lau, K. W. K., Wu, M., Wong, P. K., Pawlik, J. R. \& Qian, P. Y. (2005). Winogradskyella poriferorum sp. nov., a novel member of the family Flavobacteriaceae isolated from a sponge in the Bahamas. Int J Syst Evol Microbiol 55, 1589-1592.

Marmur, J. (1961). A procedure for the isolation of deoxyribonucleic acid from microorganisms. J Mol Biol 3, 208-218.

Marmur, J. \& Doty, P. (1962). Determination of the base composition of deoxyribonucleic acid from its thermal denaturation temperature. J Mol Biol 5, 109-118.

Nedashkovskaya, O. I., Kim, S. B., Han, S. K., Lysenko, A. M., Rohde, M., Zhukova, N. V., Falsen, E., Frolova, G. M., Mikhailov, V. V. \& Bae, K. S. (2003). Mesonia algae gen. nov., sp. nov., a novel marine bacterium of the family Flavobacteriaceae isolated from the green alga Acrosiphonia sonderi (Kütz) Kornm. Int J Syst Evol Microbiol 53, 1967-1971.

Nedashkovskaya, O. I., Kim, S. B., Han, S. K., Rhee, M. S., Lysenko, A. M., Falsen, E., Frolova, G. M., Mikhailov, V. V. \& Bae, K. S. (2004). Ulvibacter litoralis gen. nov., sp. nov., a novel member of the family Flavobacteriaceae isolated from the green alga Ulva fenestrata. Int $J$ Syst Evol Microbiol 54, 119-123.

Nedashkovskaya, O. I., Kim, S. B., Han, S. K., Snauwaert, C., Vancanneyt, M., Swings, J., Kim, K. O., Lysenko, A. M., Rohde, M. \& other authors (2005). Winogradskyella thalassocola gen. nov., sp. nov., Winogradskyella epiphytica sp. nov. and Winogradskyella eximia sp. nov., marine bacteria of the family Flavobacteriaceae. Int J Syst Evol Microbiol 55, 49-55.

Nedashkovskaya, O. I., Vancanneyt, M., Kim, S. B. \& Zhukova, N. V. (2009). Winogradskyella echinorum sp. nov., a marine bacterium of the family Flavobacteriaceae isolated from the sea urchin Strongylocentrotus intermedius. Int J Syst Evol Microbiol 59, 1465-1468.

Pinhassi, J., Nedashkovskaya, O. I., Hagström, Å. \& Vancanneyt, M. (2009). Winogradskyella rapida sp. nov., isolated from proteinenriched seawater. Int J Syst Evol Microbiol 59, 2180-2184.

Romanenko, L. A., Tanaka, N., Frolova, G. M. \& Mikhailov, V. V. (2009). Winogradskyella arenosi sp. nov., a member of the family Flavobacteriaceae isolated from marine sediments from the Sea of Japan. Int J Syst Evol Microbiol 59, 1443-1446.

Saitou, N. \& Nei, M. (1987). The neighbor-joining method: a new method for reconstructing phylogenetic trees. Mol Biol Evol 4, 406-425.

Stackebrandt, E. \& Ebers, J. (2006). Taxonomic parameters revisited: tarnished gold standards. Microbiol Today 33, 152-155. 